\title{
Effect of Transformational Leadership on Organizational Performance of Micro Finance Institutions in Kenya
}

\author{
Lydia Muriuki ${ }^{1}$, \& Kennedy B. Mwengei Ombaba ${ }^{2}$ \\ ${ }^{1}$ Ministry of Labour Social Security and Services, Kenya, \\ ${ }^{2}$ Lecturer, University of Eldoret, Dept. of Business Management, Kenya. \\ E-mail: kmwengei@gmail.com
}

Type of the Paper: Research Paper.

Type of Review: Peer Reviewed.

Indexed in: OpenAIRE.

DOI: http://doi.org/10.5281/zenodo.1248411.

Google Scholar Citation: $\underline{\text { IJMTS }}$

How to Cite this Paper:

Muriuki, Lydia., Mwengei Ombaba, Kennedy B. (2018). Effect of Transformational Leadership on Organizational Performance of Micro Finance Institutions in Kenya. International Journal of Management, Technology, and Social Sciences (IJMTS), 3(1), 88-100. DOI: http://doi.org/10.5281/zenodo.1248411.

International Journal of Management, Technology, and Social Sciences (IJMTS) A Refereed International Journal of Srinivas University, India.

(C) With Authors.

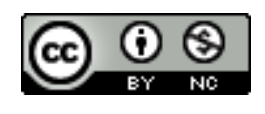

This work is licensed under a Creative Commons Attribution-Non Commercial 4.0 International License subject to proper citation to the publication source of the work.

Disclaimer: The scholarly papers as reviewed and published by the Srinivas Publications (S.P.), India are the views and opinions of their respective authors and are not the views or opinions of the SP. The SP disclaims of any harm or loss caused due to the published content to any party. 


\title{
Effect of Transformational Leadership on Organizational Performance of Micro Finance Institutions in Kenya
}

\author{
Lydia Muriuki $^{1}$, \& Kennedy B. Mwengei Ombaba ${ }^{2}$ \\ ${ }^{1}$ Ministry of Labour Social Security and Services, Kenya, \\ ${ }^{2}$ Lecturer, University of Eldoret, Dept. of Business Management, Kenya. \\ E-mail: kmwengei@gmail.com
}

\begin{abstract}
Transformational leadership has attracted extensive attention in management research. The influence of transformational leadership on organizational performance is an important aspect. Given the background where greater attention is being paid to transformational leadership in the banking industry, this research aimed to establish the degree of the influence of transformational leadership on organizational performance of micro finance institutions in Kenya. Questionnaires were used for data collection. They were analyzed via structural equation modeling. The findings reveal that organizational performance is positively influenced by transformational leadership $(\boldsymbol{\beta}=\mathbf{1 . 5 0 5} ; \mathbf{p}<\mathbf{0 . 0 5})$. These findings remind managers of the need to pay close attention to transformational leadership, to cultivate organizational performance, and thereby to eventually improve employee's sustainable performance.
\end{abstract}

Keywords: Transformational Leadership, Organizational Performance, Effectiveness, Efficiency.

\section{BACKGROUND OF THE STUDY :}

Organizations are constantly facing an increasingly dynamic environments characterized by considerable and often unpredictable economic, technological and political change. The manner in which organizations respond rapidly to such changes will ultimately have an influence eon organizational performance. Organizational performance is defined as firm performance the outcome of adapting useful management process (Mandy, 2009). According to Davood and Morteza (2012) sees firm performance as the ability of a firm to generate acceptable result and actions. Hence, firm performance is an essential issue in business activities which needs tolerable planning and dedication.

According to Mandy (2009) firm performance is considered to be the outcome of adapting useful management process. He posits that organizational performance can be measured using a number of criteria's; which includes effectiveness, efficiency, growth and productivity. Oliyo (2014) organizational effectiveness may be measured in terms of financial, operational and behavioral measures respectively. First, financial measures may include profitability and growth, which in turn can be used in assessing the financial performance of an organization. Secondly, the operational measures include productivity, resource acquisition, and efficiency and employee reaction on workflow as well as work support in organizations. Third, behavioral effective measures are made up of adaptability, satisfaction and good communication can be used to assess individual performance. This therefore study will adopt the use of effectiveness in terms of efficiency as a measure of organizational performance.

Research on organizational performance has attracted a lot of attention in academic literature. Tannenbaum and Kahn (2000) postulated that a firm's effectiveness is the capacity of the organization to successfully cope with the resources for the accomplishment of the specified goals. Consequently a shared purpose of the organisation could start with matching its resources with its goals and objectives and it 
achievement will depend in part on the fit between individuals and the culture of the organisation. The study therefore is study the relationship between organizational culture, leadership and firm performance.

Despite of many studies done few if any empirical studies have established the role of leadership on firm performance. Empirical studies and a number of meta-analyses have provided evidence of a positive relationship between transformational leadership and a range of employee outcome tested in different organizational settings (Judge and Piccoli, 2004; Dumdum, Lowe and Avolio, 2002). In addition, a meta-analyses by Piccoli et al., (2012) compared the relative importance of five leadership styles, namely; transformational, contingent reward, laissez faire, and initiating structure, and consideration in explaining job satisfaction and leaders effectiveness. The results showed that consideration and transformational leadership styles are the most important predictors of two employee outcomes. Barling, Weber and Kelloway (1996) agrees that training managers on transformational leadership behaviors resulted in significant increase in their subordinates' organizational commitment. Hence, this study seeks to establish the role of leadership on firm performance in micro finance institutions in Kenya.The study will be guided by the Trait and Factor theory of transformational leadership.

\section{THEORY AND HYPOTHESIS DEVELOPMENT :}

\subsection{Trait and Factor Theory:}

Parsons (1909) put forth a three-step schema forming the basis of the first conceptual framework of career decision making (Brown \& Brooks, 1990a) and the foundation of the vocational guidance movement (Srebalus, Marinelli, \& Messing, 1982; Super, 1983). Parsons' three-part model advocated personality analysis, where individuals gain an understanding of both their strengths and weaknesses of attributes or traits; job analysis, for instance given these traits, their conditions for success in occupations; and matching through scientific advising, make career choices based on the aforementioned information to provide the basis for career decision-making (Brown \& Brooks, 1990a; Herr \& Cramer, 1988; McDaniels \& Gysbers, 1992). Parsons' formulations are often referred to as the basis of trait and factor theory (Brown, 1990b; Brown \& Brooks, 1990b), but the work of Holland (1985) brought trait and factor theory to centre stage where it remains today. The trait theory will be used in this study to explain the moderating variable of leadership's role in moderating the relationship between organizational culture and performance.

Literature does show that transformational leadership can have a positive impact on the overall performance of the organization. Based on assertion and an understanding of the four central components of transformational leadership, a theoretical framework to understand how transformational leadership influences organizational performance was formulated. In the framework four independent variables that is idealized influence, inspirational motivation, intellectual stimulation, and individual consideration. Organizational performance as measured through effectiveness and efficiency was utilized as the dependent variable. The framework proposes that while transformational leadership may result in the development of improved organizational performance, specific elements of transformational leadership may play are more significant or substantial role in shaping performance outcomes.

Idealized influence is one of the four components of transformational leadership identified as an independent variable for this investigation. Scholars examining this process assert that idealized influence refers to the idea that followers will trust and respect leaders to provide support and resources (Chu \& Lai, 2011). Understanding the specific impact of idealized influence on organizational performance is thus imperative for expanding comprehension of how transformational leadership influences organizational outcomes. Inspirational motivation is another component of transformational leadership that is examined in this investigation as an independent variable. 
Inspirational motivation is extensively reviewed by Doody and Doody (2012) who argue that the process involves encouraging followers to align personal goals with the goals of the organization. Rawung, Wuryaningrat, and Elvinita (2015) consider the role of inspirational motivation noting its role in building trust and satisfaction for the employee. According to these authors, inspirational motivation can serves as the foundation for knowledge sharing; an important component of facilitating the success of the organization.

Intellectual stimulation represents an important component of transformational leadership and is also included as an independent variable for evaluation. A review of this variable suggests that intellectual stimulation facilitates follower empowerment through communication and encouragement to identify problems and solutions (Smothers, Doleh, Celuch, Peluchette, \& Valadares, 2016). The role of intellectual stimulation on organizational performance has been evaluated more extensively in the literature as an independent variable shaping outcomes for employees in the organization. In particular, Anjali and Anand (2015) assert that intellectual simulation leads to the development of employee commitment to the organization. This, in turn, has implications for the ability of the organization to achieve goals based on the dedication and hard work of employees (Anjali \& Anand, 2015).

According to Zacher, Pearce, Rooney, and McKenna (2014) individual consideration is a process involving the willingness and ability of the leader to provide nurturing support for his/her followers. In terms of the implication of individual consideration for organizational performance, Snell, Stanley, Zhang, and Almaz (2013) argue that this process can positively influence employee job satisfaction, leading to higher levels of engagement and motivation within the organization. When all employees experience this outcome organizational performance should improve (Snell et al., 2013).

\subsection{Concept of Organizational Performance:}

Performance is defined as the ability (both physical \& psychological) to execute a specific task in a specific manner that can be measured as high, medium or low in scale (Uddin et al., 2013). The word 'performance' can be used to describe different aspects such as societal performance, organizational performance, employee performance, and individual performance etc. Researchers (Roe, 1999) tend to identify two dimensions of performance: an action dimension (that is behavioral aspect) and an outcome dimension (i.e. performance aspect). Cascio (2014)and Kaplan and Norton (2001)) defined organizational performance as the degree of accomplishment of work or mission as measured in terms of work outcome, intangible assets, customer link, and quality services. This is helpful in evaluating the achievement of the organizational goals as well as when developing strategic plans for the organizations' future performance (Ittner \& Larcker, 2012).

Table 1: Distribution of Respondent Category

\begin{tabular}{|l|l|l|l|}
\hline Category & Population & Percentage & Respondents \\
Top Management & 86 & $86 / 236^{*} 148$ & 54 \\
Administrative staff & 58 & $58 / 236^{*} 148$ & 36 \\
Support staff & 92 & $92 / 236^{*} 148$ & 58 \\
Total & $\mathbf{2 3 6}$ & & $\mathbf{1 4 8}$ \\
\hline
\end{tabular}

Although there is a range of behaviors that could be used for measuring performance, Borman and Schmit (2012) stress it is judgmental and evaluative processes that take a great deal of action when defining performance. Ittner and Larcker (2012) confers that organization performance is a broader concept whose indicators include productivity, quality, consistency, efficiency as well as relative measures such as management development and leadership training for building necessary skills and attitudes among the workers (Richard, 
2002). Organizational performance can also be conceptualized in terms of net income, revenue, number of employees, physical expansion, increased market share and financial sustainability (Kotter, 2012).

The degree of an achievement to which an employee's fulfill the organizational mission at workplace is called performance (Cascio, 2006).

Transformational Leadership

Idealized influence

Inspirational motivation

Intellectual stimulation

Individual Consideration
Performance has been perceived differently by various researchers, but most of the scholars relate performance with measurement of transactional efficiency and effectiveness towards organizational goals (Stannack, 1996; Barne, 1991).

Organizational Performance

Efficiency

Effectiveness

The descriptive survey design enables the researcher to explore and describe the relationship between variables in their natural

\section{TARGET POPULATION :}

Cooper and Schindler (2001) define population as the total collection of entities to whom the researcher seeks to make inferences. Thus, population is the collection of all entities that conform to a given study condition. The top management, middle management lower management of the 43 micro finance institutions in Nairobi city (CBK, 2016) constituted the subjects of the study. The study singled out Nairobi city since it is the headquarters of most micro finance institutions in Kenya. The target population consist of 43 micro finance institutions in Nairobi town. There are 236 employees distributed in different cadres of

\subsection{Data Collection Tools}

The type of data will be primary data collected using a structured questionnaire which will be issued to sample units of the micro finance institutions. Hence, transformational leadership will be measured on a five-point Likert scale.

\subsection{Data Collection Instruments}

The data will be collected using questionnaires. The items in the questionnaire will be measured on a 5-point Likert response scale ranging from "Strongly disagree" to "Strongly agree" as guided by prior studies. setting. This design is suitable because it enables the researcher to formulate important principle of knowledge.

management in institutions.

\section{SAMPLING DESIGN SIZE :}

Stratified random sampling method will be applied to come up with the strata, since the population in manufacturing firms is heterogeneous.

The study will be guided by Cochran (1963) and Yamane (1967) to determine the sample size.

Therefore the formula as simplified by Yamane 1967 is:

$$
\begin{array}{ll}
=\mathrm{n}=\frac{236}{1+236(0.05)^{2}}=148.42=148 \\
n=\frac{N}{1+N(e)^{2}} \quad \begin{array}{l}
\text { Where: } \mathrm{n} \text { is the sample size. } \mathrm{N} \text { is the total population size and } \mathrm{e} \text { is the } \\
\text { error } / \text { level of precision which is } 0.05 .
\end{array}
\end{array}
$$

\subsection{Validity and Reliability Validity}

Content validity will be estimated by a thorough review of the relevant literature and consultation with subject matter experts, to determine whether the items in the measure have adequately sampled the domain. To enhance the concept validity of the survey measures, the researchers conducted a pretest (Fowler, 1993) and a pilot study to assist us in the fine tuning of the questionnaire, and particularly in identifying potentially misleading items(Carpenter \&Westphal, 2001). 


\section{Reliability}

The researchers employed Test-retest reliability which will indicate the extent to which a measure gives the same result on two (or more) repeated administrations (Tharenouet. al., 2007). The questionnaires will be considered reliable for the study since they will be modeled upon instruments in research literature that have been pre-tested in previous studies and yielded desired results. Internal consistency of the items in the questionnaire will be tested by computing Cronbach's alpha reliability as per (Sekeran, 2000). The Cronbach's reliability coefficient should confirm to the acceptable guideline of $\alpha$ $=.70 \mathrm{Wan}$ and Ong (2005).

\subsection{Data Analysis and Presentation Preparation of Data for Analysis}

After data collection, the data obtained from the field was filled-in and returned questionnaires were edited for completeness, coded and entries made into Statistical package for social sciences (SPSS version 21). Screening was then performed for the following; levels of measurements, sample size, assumptions of normality, linearity, independence of errors and homoscedasticity. Further screening covered outlier detection and establishing presence of multicollinearity. Testing for compliance with statistical assumptions of multivariate analysis provided a pillar for making statistical inferences and results. This ensured that the data are accurate, consistent with other information, uniformly entered, complete and arranged to simplify coding and tabulation. With data entry, the data collected was captured and stored. Descriptive and inferential analysis was conducted.

\section{DATA ANALYSIS, PRESENTATION AND INTERPRETATION :}

\subsection{Preliminary Screening of Data: Response Rate}

The study achieved a response rate of $73.1 \%$ with 108 respondents reached, out of the 148 targeted. According to Mugenda and Mugenda (2003) a response rate of $50 \%$ is adequate for analysis and reporting; a rate of $60 \%$ is good and a response rate of $70 \%$ and over is excellent.

The study performed the Missing Value
Analysis (MVA) with a view to check for any missing data pattern as well as the respective magnitude of the missing values. The operation was modeled to underscore pattern of missing values and to replace them in the data set. The subsequent univariate statistics computation revealed that the percentage and count of missing values for all items were less than $5 \%$.

In view of the fairly large sample size of the data set, the missing values percentage was deemed negligible and the missing values were thus replaced with the series mean of the items under study. This is in tandem with most studies with considerably large sample sizes attributable to the fact that most procedures for handling missing values would be expected to yield similar results. As for the nature of missing data, the data was analyzed to establish whether it was missing at random (MAR), missing completely at random (MCAR), and missing not at random (MNAR).

\section{Bivariate and Multivariate Normality,} Skewness and Kurtosis

Normality of variables in the data set was examined using a measure of skewness and kurtosis. Whereas the basis of whether data is normally distributed varies, as a rule of thumb, the values for asymmetry and kurtosis between 2 and +2 are considered acceptable in order to prove normal univariate distribution (George \&Mallery, 2010). Skewness values range from 2.00-3.00 and kurtosis value ranging from 7.021.00 show that they are moderately non-normal while values above 3.00 for skewness and greater than 21.00 for kurtosis show extreme lack of normality (Bryne, 1998). Accordingly, the score of skewness and kurtosis on each item was analyzed and reported. Items found to lack normality were evaluated and accordingly, either transformed using log-transformation, removed from further analysis or retained. All items were found to be within the acceptable range.

\section{Test of Multicollinearity}

Multicollinearity refers to the linear correlation among variables. It occurs when two or more predictors in the model are correlated and provide redundant information about a response. To check for correlated variables, multicollinearity was tested using variance 
inflation factor (VIF). A VIF for all the independent and dependent variables less than 3 $(\mathrm{VIF} \leq 3)$ shows no multicollinearity while a VIF of more than 10 (VIF $\geq 10$ ) indicates a problem of multicollinearity (Cohen et al., 2003). Multicollinearity creates a problem for multiple regression models given that as collinearity increases the standard error of coefficients also increases making them less reliable. In this regard, the present study performed a multicollinearity test with a view to identify variables with a high correlation among themselves. All variables were found to be optimally correlated.

\subsection{Demographic Information:}

This section captures both the respondent organizations' demographics including responses by gender of the respondent, managerial position, respondent age, number of years in service and highest education level attained presented and analyzed in table 2 below.

Table 2: Response by Gender

\begin{tabular}{|l|r|r|}
\hline Gender & Frequency & Percent \\
\hline Male & 84 & 78.0 \\
\hline Female & 24 & 22.0 \\
\hline Total & 108 & $\mathbf{1 0 0 . 0}$ \\
\hline $\begin{array}{l}\text { Management } \\
\text { level }\end{array}$ & Frequency & Percent \\
\hline $\begin{array}{l}\text { Top } \\
\text { management } \\
\text { level }\end{array}$ & 33 & 30.4 \\
\hline $\begin{array}{l}\text { Middle } \\
\text { management } \\
\text { level }\end{array}$ & 54 & 49.6 \\
\hline Support Staff & 21 & 20.0 \\
\hline Total & 108 & 100.0 \\
\hline Age Categories & Frequency & Percent \\
\hline Below 30 years & 17 & 15.7 \\
\hline 30-40 years & 41 & 37.9 \\
\hline 41-50 years & 32 & 29.7 \\
\hline $51-60$ years & 18 & 16.7 \\
\hline
\end{tabular}

\begin{tabular}{|l|r|r|}
\hline Total & $\mathbf{1 0 8}$ & $\mathbf{1 0 0 . 0}$ \\
\hline $\begin{array}{l}\text { Length of } \\
\text { Service }\end{array}$ & Frequency & Percent \\
\hline $0-5$ & 30 & 27.8 \\
\hline $6-10$ & 19 & 17.6 \\
\hline $11-15$ & 22 & 20.4 \\
\hline $16-20$ & 25 & 23.1 \\
\hline Over 20 years & 12 & 11.1 \\
\hline Total & 108 & 100 \\
\hline $\begin{array}{l}\text { Highest } \\
\text { Education level }\end{array}$ & Frequency & Percent \\
\hline $\begin{array}{l}\text { Primary } \\
\text { Certificate }\end{array}$ & 2 & 1.9 \\
\hline Diploma & 58 & 53.7 \\
\hline Undergraduate & 36 & 33.3 \\
\hline Postgraduate & 12 & 11.1 \\
\hline Total & 108 & 100.0 \\
\hline
\end{tabular}

Source: Survey Data, 2017

In order to show the gender distribution and parity across the institutions included in the survey, the study sought to determine the respondents' gender. Respondents were thus required to indicate by checking either male of female response categories provided. As presented in table 4.1, male respondents, 84 (78.0\%), registered the most as compared to their female counterparts, 24 (22.0\%). It follows then from the findings, that the males make the dominant gender. This is a notable finding with the implication that the empowerment of the female gender has not made great strides in the country much to their numbers matching those of their male counterparts in key managerial positions.

Respondents were asked to indicate their management levels in order to further ascertain representation and diversity thereof in perspectives. To this end, three managerial cadres were targeted in the present study purposively owing to their expected possession of the information of interest with respect to the variables. The analysis revealed that a majority, $49.6 \%$ of the respondents were in the middle management level while $20 \%$ belonged to the 
senior management level and 30.6\% belonged to support staff. This indicates the diverse perspectives as informed by tasks and duties characteristic of the respective management levels. All categories were deemed adequate for analysis as regards the response rates and representative of employees across the two levels of management among the institutions surveyed, and by extension, similar institution in the country.

The study deemed age an important demographic characteristic in the present study with a view to establish any pertinent trends in the variables under study as well as to have an overview of the age distribution thereof. Age was also considered a relative indictor of respondents' length of experience hence reliability of responses. Results as illustrated in table 4.1 reveal that a majority of respondents, $37.9 \%$ fall within the 30 - 40 years age category. This is quite distantly followed by those within the 41 - 50 years age category as indicated by $29.7 \%$ of the respondents. Only $16.7 \%$ and $15.7 \%$ of respondents fall between 51 - 60 years and less than 30 years categories respectively. As such, it can be deduced that age, across the institutions surveyed is majorly youthful to middle age, distributed, between 30 and 50 years. A rich diversity in experience was thus established.

With some level of working experience necessary in establishing the study objectives, the study found it appropriate to establish the length of service of the respondents, in years, serving at their respective institutions. This would ascertain that responses were already informed by diverse experience owing to respondents' respective lengths of service. The study found that a majority of respondents, $27.8 \%$ have worked in the study area for less than 5 years. This was followed by those having worked for between 16 and 20, as indicated by $23.1 \%$ of the respondents while $20.4 \%$ of the respondents have worked for 11 and 15 years. Only $11.1 \%$ of the respondents were found to have worked in their respective institutions for either between 16 and 20 years and over 20 years. The results present a rather fair skewed distribution across the years representing the length of experience. With a majority of respondents having worked for at least 5 years, responses can be deemed as informed by adequate experience in the study area.

Respondents were also asked to indicate their highest levels of education. This would serve to show the academic qualification among respondents in their respective positions, as well as a general overview of education levels among respondents in their respective study areas. From the findings, a majority of respondents, $53.7 \%$ of respondents indicated having attained a diploma level, followed by $33.3 \%$ having attained either an undergraduate degree. A further $11.1 \%$ indicated having attained a diploma or higher national diploma. Overall, the study area can be said to comprise staff from relatively high levels of education.

\subsection{Organizational Performance:}

In this section, the study sought the respondents' perception regarding the various aspects defining organizational performance. The set of statements used in this regard was first pretested in a pilot study in order to determine its reliability, evaluated through Cronbach's Alpha which measures the internal consistency.

\section{Reliability Test Results}

The Alpha measures internal consistency by establishing if certain items measure the same construct. Nunnally (1978) established the Alpha value threshold at 0.7 which the study benchmarked against. Cronbach Alpha was established for every objective in order to determine if each scale (objective) would produce consistent results should the research be done later on. Table 3 below presents the findings. 
International Journal of Management, Technology, and Social

Table 3: Reliability Coefficients

\begin{tabular}{|l|l|l|l|l|l|}
\hline Composite scale & $\begin{array}{l}\text { Initial } \\
\text { items }\end{array}$ & $\begin{array}{l}\text { Final } \\
\text { items }\end{array}$ & $\begin{array}{l}\text { Grand mean } \\
\text { (Standard } \\
\text { deviation) }\end{array}$ & $\begin{array}{l}\text { Initial Cronbach's } \\
\text { Alpha }\end{array}$ & $\begin{array}{l}\text { Final Cronbach's } \\
\text { Alpha }\end{array}$ \\
\hline $\begin{array}{l}\text { Employee } \\
\text { Performance } \\
\text { Leadership }\end{array}$ & 14 & 14 & $\begin{array}{l}(\mathrm{M}=53.419 ; \\
\mathrm{SD}=6.4645) \\
(\mathrm{M}=25.350 ; \\
\mathrm{SD}=3.427)\end{array}$ & .810 & .810 \\
\hline
\end{tabular}

Source: Pilot Study, 2017

The reliability coefficients table shows that all the sub-scales for organizational performance, culture and leadership variables were significant, having an alpha above the prescribed threshold of 0.7. The study thus found that the variables as measured in the questionnaire was reliable and could thus be used in the main study and therefore analysis.

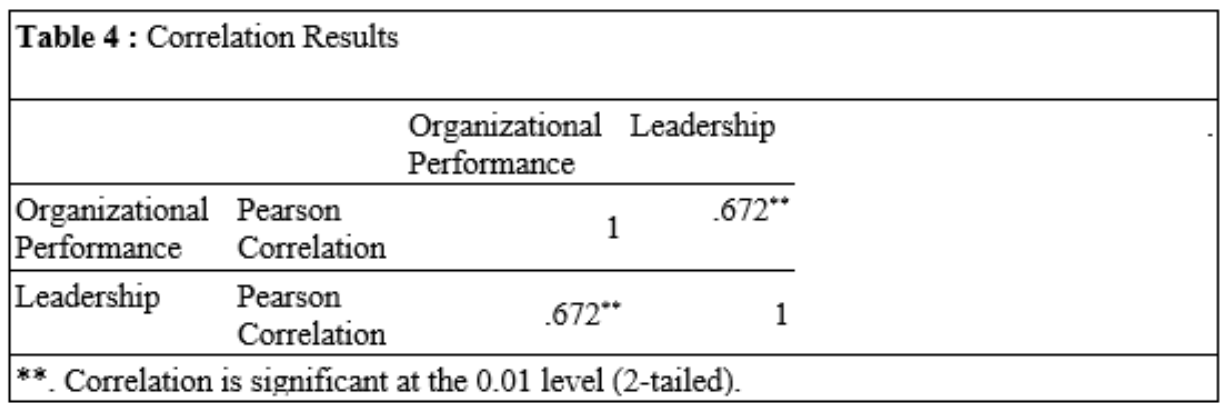

\subsection{Transformational Leadership and}

\section{Organizational Performance:}

The study also sought to examine the effect of transformational leadership on organizational performance among micro finance institutions in Kenya. This informed the second hypothesis of the study $\left(\mathrm{H}_{02}\right)$ that there is no significant relationship between transformational leadership on organizational performance among micro finance institutions in Kenya. This hypothesis was tested through Pearson product moment correlation (r) to show the extent of the relationship, guided by the model: $\mathrm{Y}=\alpha+$ $\beta_{1}$ Xwhere $\alpha$ is the constant (intercept), $Y=$ Organizational performance, $\beta 1$ and $\beta_{4}$ are the beta Coefficients while $X$ and represent Transformational leadership and $\varepsilon$ is the Error Term. The results of the correlation are presented in table 5 below.

Table 5: Relationship between Transformational leadership and Organizational performance

\begin{tabular}{|c|c|c|c|}
\hline & & $\begin{array}{l}\text { Organizational } \\
\text { Performance }\end{array}$ & $\begin{array}{c}\text { Transformational } \\
\text { Leadership }\end{array}$ \\
\hline Organizational performance & $\begin{array}{l}\text { Pearson Correlation } \\
\text { Sig. (2-tailed) }\end{array}$ & 1 & \multirow{3}{*}{ 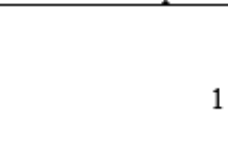 } \\
\hline \multirow{2}{*}{ Transformational Leadership } & Pearson Correlation & $.198^{* *}$ & \\
\hline & & .000 & \\
\hline \multicolumn{2}{|c|}{ **. Correlation is significant at the 0.01 level (2-tailed). } & & \\
\hline \multicolumn{2}{|c|}{$\mathrm{N}=108$} & & \\
\hline \multicolumn{2}{|l|}{ Source: Survey Data, 2017} & & \\
\hline
\end{tabular}

Table above presents the Pearson correlations for the relationships between transformational leadership on organizational performance among micro finance institutions in Kenya. From the 
findings, a positive correlation was established, that was statistically significant $(\mathrm{r}=.198$; $\mathrm{P}$ value $=.000$ ) at either 0.01 level or 0.05 level of confidence. The positive significant correlation is of the implication that as transformational leadership is increased, organizational performance meaningfully increases as well.

The study thus fails to accept the second null hypothesis of the study that states that there is no significant relationship between transformational leadership and organizational performance among selected micro financial institutions in Kenya and accepts the alternative hypothesis that states that there is a significant relationship between transformational leadership and organizational performance among selected micro financial institutions in Kenya.

5.5. The Effect of Transformational Leadership and Organizational Performance:

To establish the the effect of transformational leadership and organizational culture on organizational performance among micro finance institutions in Kenya, a regression analysis was conducted, with the assumption that: variables are normally distributed to avoid distortion of associations and significance tests, which was achieved as outliers were not identified; a linear relationship between the independent and dependent variables for accuracy of estimation, which was achieved as the standardized coefficients were used in interpretation.

The regression model was as follows:

$\mathrm{Y}=\alpha+\beta_{1} \mathrm{X}+\varepsilon$

Where

$\mathrm{Y}=$ organizational performance

$\alpha$ is the y-intercept or model coefficient;

$\beta_{1}-\beta_{4}$-are the coefficients of the independent variables;

$\mathrm{X}=$ transformational leadership

$\varepsilon$ is the error term established from

heteroscadiscity test;

Table $6 i$ The effect of transformational leadership and organizational culture on performance

\begin{tabular}{|lcrrr|}
\hline \multicolumn{4}{c|}{ Model Summary } \\
\hline Model & R Square & Adjusted R Square & \multicolumn{2}{c|}{$\begin{array}{c}\text { Std. Error of the } \\
\text { Estimate }\end{array}$} \\
1 & \multicolumn{2}{c}{.522} & .519 & \\
a. Predictors: (Constant), Transformational, & & & \\
\hline
\end{tabular}

\begin{tabular}{|c|c|c|c|c|c|c|}
\hline \multicolumn{7}{|c|}{ ANOYAa } \\
\hline \multirow[t]{2}{*}{ Model } & & Sum of Squares & $f$ & Mean Square & F & \\
\hline & Regression & 14859.380 & 2 & 7429.690 & 172.388 & $.000^{b}$ \\
\hline \multirow[t]{2}{*}{1} & Residual & 13619.178 & 316 & 43.099 & & \\
\hline & Total & 28478.558 & 318 & & & \\
\hline
\end{tabular}

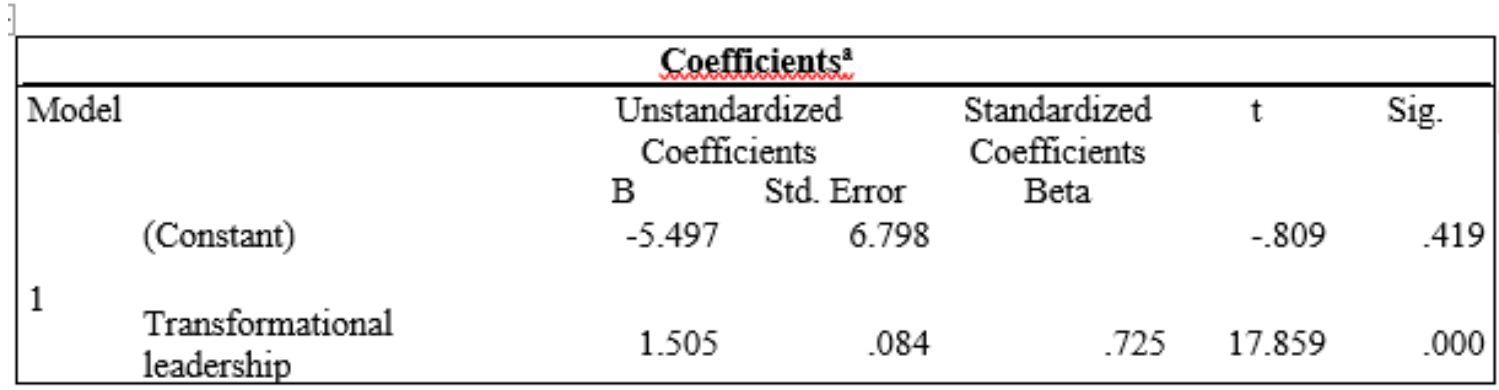

Dependent Variable: Organizational Performance

Source: Survey Data, 2017

Regression analysis produced the coefficient of determination and analysis of variance
(ANOVA). Analysis of variance was done to show whether there is a significant mean 
difference between dependent and independent variables. The ANOVA was conducted at 95\% confidence level. According to Katz (2006) Regression analysis generates an equation to describe the statistical relationship between one or more predictor variables and the response variable.

Regression analysis was used to establish the strengths of relationship between organizational performance (dependent variable) and the constituents, that is, Transformational leadership, (independent variables). The results showed a correlation value (R) of 0.722 which depicts that there is a good linear dependence between the independent and dependent variables.Chaplin (2007) argues that R-squared is a statistical measure of how close the data are to the fitted regression line. It is also known as the coefficient of determination, or the coefficient of multiple determination for multiple regression.

With an adjusted R-squared of 0.519 , the model shows that transformational leadership, explain 51.9 percent of the variations in organizational performance while 48.1 percent is explained by other factors not included in the model. According to Howell (2002), measures of goodness of fit typically summarize the discrepancy between observed values and the values expected under the model in question.

The P-value of 0.000 implies that transformational leadership, has a significant relationship which is significant at a confidence interval of 0.01 level to 0.05 level and the $\beta=$ 1.505. This means that transformational leadership influence organizational performance. This also depicted the significance of the regression analysis done at 95\% confidence level. This implies that the regression model is significant and can thus be used to assess the association between the dependent and independent variables. Gelman (2006) provides that ANOVA statistics analyzes the differences between group means and their associated procedures (such as "variation" among and between groups).

The data in table 4.31 reveals that transformational leadership affects organizational Performance positively. Taking the regression model: $\mathrm{Y}=\alpha+\beta_{1} \mathrm{X}+\varepsilon$; where, $\mathrm{Y}=$ performance of micro finance institutions; $\alpha$ $=$ Constant; $\beta_{1}-\beta_{2}=$ coefficients of the independent variables; $X=$ transformational leadership and $\varepsilon=$ being the error term established from heteroscadiscity.

This finding is in line with De Jong and Bruch (2013) who established that transformational leadership has a direct impact on organizational climate. De Jong and Bruch argue that through transformational leadership the climate of the organization can be strengthened creating an environment in which employees are motivated and energized. This facilitates the achievement of organizational goals and hence increased performance. The study supports Orabi 2016 who established that transformational leadership has a positive influence on organizational performance of banking sector in Jordan.

\section{SUMMARY :}

The objective of the study was to examine the effect of transformational leadership on employee performance among micro finance institutions in Nairobi Kenya. This also informed the second hypothesis of the study that there is no significant relationship between transformational leadership on employee performance among micro finance institutions in Nairobi Kenya. The positive significant correlation is of the implication that as transformational leadership is increased, organizational performance meaningfully increases as well. The study thus rejected the second null hypothesis of the study that states that there is no significant relationship between transformational leadership on employee performance among micro finance institutions in Nairobi Kenya.

Findings reveal that transformational leadership significantly determines organizational performance among micro finance institutions in Nairobi Kenya. It can be deduced therefore that transformational leadership is a crucial factor in achieving organizational success through improved employee performance. For transformational leadership to translate to superior employee performance, the organization ought to streamline other 
fundamental organizational factors including employee motivation, employee satisfaction, compensation, training and development, job security, organizational structure and others.

\section{REFERENCES :}

[1] Anjali, K.T., \& Anand, D. (2015). Intellectual stimulation and job commitment: A study of IT professionals. IUP Journal of Organizational Behavior, 14(2), 28-41. http://www.iupindia.in/Organizational_Beh avior.asp.

[2] Barling J., Slater F., Kevin K. E. (1996).Transformational leadership and emotional intelligence: an exploratory study.

[3] Cascio, W. F. (2006). Managing Human Resources: Productivity, Quality of Life, Profits. McGraw-Hill Irwin.

[4] Cooper, D.R, \& Schindler, P.S. (2008) Business Research Methods, Tata McGrawHill.

[5] Chu, L., \& Lai, C. (2011). A research on the influence of leadership style and job characteristics on job performance among accountants of county and city government in Taiwan. Public Personnel Management, 40(2), 101-118. doi: 10.1177/009102601104000202.

[6] De Oliveira Rodriguez, A., \& Ferreira, M.C. (2015). The impact of transactional and transformational leadership style on organizational citizenship behaviors. PsicoUSF, 20(3), 493-504. doi: 10.1590/14138271201520031

[7] Denison, D. (1984). Bringing corporate culture to the bottom line. Organizational Dynamics, 13(2), 5-22.

[8] Doody, O., \& Doody, C.M. (2012). Transformational leadership in nursing practice. British Journal of Nursing, 21(20), 1212-1218

http://info.britishjournalofnursing.com/

[9] Dumdum, U. R., Lowe, K. B., \&Avolio, B. J. (2002). A meta-analysis of transformational and transactional leadership correlates of effectiveness and satisfaction: An update and extension.

[10] Judge T. A and Piccolo R. F. (2004). Transformational and Transactional Leadership: A Meta-Analytic Test of Their Relative Validity Journal of Applied Psychology 2004, Vol. 89, No. 5, 755-76.

[11] Kothari, C. (2004). Research Methodology: Methods and Techniques. 2nd edition. New age International Publishers, New Delhi, India.

[12] Mugenda, O and Mugenda, A. G. (2003). Research Methods: Quantitative and Qualitative approaches. Nairobi: Acts Press.

[13] Ogbonna, E and Harris, L. (2000). Leadership style, organizational culture and performance: Empirical evidence from UK companies. International Journal of Human Resources Management, 11(4), 766-788.

[14] Piccolo, R. F.,Bono, J., Heinitz, K., Rowold, J., Du ehr, E., and Judge, T . A. (2012). The Relative Impact of Complementary Leader Behaviors: Which Matter Most?, Leadership Quarterly, Vol 23, pp 567-581.

[15] Rawung, F.H., Wuryaningrat, N.F., \&Elvinita, L.E. (2015). The influence of transformational and transactional leadership on knowledge sharing: An empirical study on small and medium business in Indonesia. Asian Academy of Management, 20(1), 123-145. http://web.usm.my/aamj/

[16] Sekaran, U. (2000).Research Methods for Business: A skill-building approach, $3^{\text {rd }}$ edition. New York: John Wiley.

[17] Sekaran, U. \&Bougie, R. (2010). Research methods for Business: A Skill building approach. UK: John Wiley \& Sons.

[18] Smothers, K., Doleh, R., Celuch, K., Peluchette, J., \& Valadares, K. (2016). Talk nerdy to me: The role of intellectual stimulation in the supervisor-employee 
relationship. Journal of Health \& Human Services Administration, 38(4), 478-508. http://www.spa ef.com/jhhsa.php

[19] Snell, R.S., Yi, Z., \&Chak, A.M.K. (2013). Representational predicaments for employees: Their impact on perceptions of supervisors' individualized consideration and on employee job satisfaction. International Journal of Human Resource Management, 24(8), 1646-1670. DOI: 10.1080/09585192.2012.723634.

[20] Uddin, Luva R. H \& Hossian M (2013). Impact of Organizational Culture on Employee Performance and Productivity: A Case Study of Telecommunication Sector in
Bangladesh.International Journal of Business and Management; 8(2), 63-77.

[21] Wan, D. \& Ong, C. H. (2005). Board structure, process, and performance: Evidence from public- listed companies in Singapore. Corporate Governance: An International Review, 13: 277- 290. 